\title{
Epidemiology, Mechanisms, Diagnosis, and Treatment of Delirium: A Narrative Review
}

\author{
Juan Pablo Ospina, MD ${ }^{1,2}$; Franklin King IV, MD ${ }^{1,2}$; \\ Elizabeth Madva, MD ${ }^{1,2}$; Christopher M. Celano, MD ${ }^{1,2 *}$ \\ ' Department of Psychiatry, Massachusetts General Hospital, Boston, Massachusetts, USA \\ ${ }^{2}$ Harvard Medical School, Boston, Massachusetts, USA
}

\begin{abstract}
Delirium is an acute disorder of arousal and attention that is commonly encountered, incompletely understood, and associated with adverse outcomes including increased morbidity and mortality, reduced health-related quality of life, and increased healthcare costs. In this narrative review, we examine the epidemiology, potential pathophysiological mechanisms, assessment, prevention, and treatment of this cognitive disorder. Delirium impacts up to $30 \%$ of hospitalized adults and most commonly affects patients with advanced age, cognitive decline, and medical or surgical comorbidity. While not fully understood, delirium is characterized by widespread dysfunction in inflammation, neurotransmitter and neurohormonal signaling, and structural abnormalities within the blood-brain barrier and brain parenchyma. Numerous screening assessments exist for delirium, but a clinical interview with cognitive examination is the gold standard for diagnosis. Prevention and early identification of delirium has the potential to be more effective than treatment of delirium, which requires the reversal of the underlying medical cause. Antipsychotic medications are used frequently for the management of acute agitation related to delirium, though there is little evidence for the efficacy of pharmacologic interventions. Further research into the pathophysiology, diagnosis, prevention, and treatment of delirium is greatly needed to reduce the incidence and sequelae of this common illness.
\end{abstract}

\section{Introduction}

Delirium is defined as an acute disturbance of arousal, attention, and orientation, accompanied by disturbances in perception, emotion, memory, and psychomotor activity that is caused by an underlying medical illness or substance $[1,2]$. Although common, it is under-recognized, its pathophysiology is poorly understood, and treatment options are limited; moreover, it is associated with increased morbidity, mortality, and healthcare costs [3]. Despite increasing clinical interest in delirium, recent reviews have been limited in scope, focusing on either subtopic within delirium (i.e., diagnosis, prevention, treatment, etc.) or specific patient populations. Accordingly, we performed a narrative review of the literature focusing on the epidemiology, pathophysiology, diagnosis, prevention, and management of delirium across patient populations. This review summarizes the current understanding of delirium, highlighting recent advances in clinical approach, areas of uncertainty, and recommendations for management.

\section{Epidemiology}

\section{Incidence and Prevalence of Delirium}

Delirium is a common syndrome that affects up to $30 \%$ of hospitalized adults [4]. The prevalence varies significantly depending on the patient population, as patients with advanced age, cognitive decline, and more severe medical illness are at higher risk. Most studies have explored delirium in the hospital setting and almost always in older individuals (e.g., $>65$ years), rather than in the general population [5]. While relatively uncommon in the outpatient setting [6], delirium affects nearly $20 \%$ of patients over age 75 on medical inpatient units when formally assessed by experienced clinicians [7]. In intensive care unit (ICU) settings the prevalence is significantly higher, where rates of over $80 \%$ have been reported in mechanically ventilated patients [8]. Finally, among patients who have undergone surgery, the incidence of post-operative delirium ranges from $13 \%$ to over $50 \%[9,10]$; a recent meta-analysis of 37 studies in patients over age 60 undergoing elective surgery found the pooled incidence of post-operative delirium to be nearly $19 \%$ [9].
It is notable that even within specific treatment settings, reported rates of delirium prevalence vary widely. For example, in the ICU setting, the prevalence of delirium has ranged from $20 \%$ to over $80 \%[8,11]$. Some variability is likely attributable to study design (e.g., frequency of assessment), the method used to diagnose delirium (e.g., clinical evaluation vs. screening instrument), patient characteristics, and site-specific factors, such as practice patterns related to the use of sedative and analgesic medications [12].

\section{Links Between Delirium and Health Outcomes}

Delirium is associated with a multitude of adverse clinical outcomes, including longer time to extubation and increases in length of stay in both ICU [13] and general medical settings [14], thus putting patients at risk for additional medical complications associated with prolonged hospitalization [3]. Patients also face an increased risk of nursing facility placement or hospital readmission [3], and, following surgery, are also at increased risk of post-operative complications [9].

In the longer term, patients with delirium demonstrate accelerated cognitive and functional decline and an increased incidence of dementia [15]. Of greatest concern, elderly patients with delirium face increased mortality, with a meta-analysis finding a 95\% increased hazard for mortality for delirious patients compared to non-delirious controls, even after adjusting for confounding variables [16]. Delirium is also associated with increased healthcare utilization, with estimated costs of between $\$ 16,303$ to $\$ 64,421$ per patient and an annual national burden of $\$ 143-152$ billion per year in the United States [17]. These costs appear to primarily be related to prolonged hospitalization, higher costs per hospital day (e.g., longer ICU stay), and higher rates of nursing home placement and home health needs $[17,18]$.

\section{Pathophysiology of Delirium}

The pathophysiology of delirium is complex, multifactorial, and incompletely understood, with multiple different mechanisms contributing to the symptoms of this clinical syndrome. Several abnormalities have been described and different hypotheses developed (Table 1) to explain the changes in arousal, cognition, and perception that are the hallmarks of this disorder. 
Table 1. Mechanisms Involved in Delirium Pathophysiology

\begin{tabular}{|c|c|}
\hline Type of Mechanism & Specific Abnormalities \\
\hline \multirow{3}{*}{ Anatomic Abnormalities } & Vascular: Reduced blood flow in frontal and parietal lobes and pons. \\
\hline & Structural: Microstructural damage in cerebellum, hippocampus, thalamus, and basal forebrain. \\
\hline & $\begin{array}{l}\text { Functional: Increased coupling between dorsolateral prefrontal cortex and posterior cingulum cortex, } \\
\text { and decreased coupling between thalamic, caudate, and other subcortical regions. }\end{array}$ \\
\hline \multirow{2}{*}{ Neurotransmitter Imbalance } & Increased dopamine, noradrenaline and glutamate and reduced acetylcholine. \\
\hline & Variable alterations in serotonin, histamine, and GABA. \\
\hline Inflammation & $\begin{array}{l}\text { Increased IL-1 } \beta \text {, IL-6, IL-8, adiponectin, and protein C leading to disruption of blood brain barrier } \\
\text { permeability, neuronal apoptosis, and synaptic dysfunction. }\end{array}$ \\
\hline Hormonal Dysregulation & Abnormally elevated cortisol and decreased melatonin. \\
\hline \multirow{2}{*}{ Others } & Decreased oxidative metabolism. \\
\hline & Age-related microstructural damage. \\
\hline
\end{tabular}

GABA, gamma-amino butyric acid; IL-1 $\beta$, interleukin-1 $\beta$; IL-6, interleukin-6; IL-8, interleukin-8.

\section{Anatomic Abnormalities}

Delirium has been postulated to be caused by dysfunction in structures mediating attention, affecting the bilateral frontal lobes, primary motor cortex, right parietal lobe, thalamus and brainstem [19]. Recent neuroimaging studies have supported this idea while further elucidating localization of deficits. A study examining cerebral blood flow with single photon emission computed tomography found variable reductions in frontal, parietal and pontine regions, consistent with the role of frontal-parietal networks in attention, orientation, and cognitive control, and pontine involvement in arousal and wakefulness [20]. Another study, which examined microstructural damage in white and grey matter with diffusion tensor imaging, found abnormalities in the cerebellum, hippocampus, thalamus, and basal forebrain [21]. Clinically, these abnormalities are consistent with many of the deficits encountered in delirium, with the basal forebrain being critical in arousal, the hippocampus and temporal lobe in memory and visuospatial abilities, and the fronto-thalamic network in attention. In addition to abnormalities in specific brain structures, specific networks have also been implicated. For example, a recent study found increased resting state functional connectivity between the dorsolateral prefrontal cortex and the posterior cingulate cortex, and decreased connectivity between thalamic, caudate, and other subcortical regions [22]. Taken together, these findings highlight the multinetwork involvement of delirium with involvement of the default mode network, executive control areas, and subcortical structures. The abnormalities described likely represent accumulated structural damage and loss of connectivity that leaves patients vulnerable to delirium when exposed to increased stressors such as acute medical illness or surgery [21].

\section{Neurotransmitter Imbalance}

At the molecular level, delirium is thought to arise from a neurotransmitter imbalance leading to excess release of dopamine and reduced availability of acetylcholine [23]. This hypothesis is supported by epidemiological studies that have shown both anticholinergic medications and dopamine administration to be independent risk factors for the development of delirium [24,25]. Similarly, increases in other excitatory neurotransmitters such as glutamate and noradrenaline have been described, as well as variable alterations of gamma-amino-butyric acid (GABA), serotonin, and histamine, although evidence is conflicting or not well understood $[26,27]$.

\section{Inflammation}

Among the best characterized risk factors in delirium is inflammation, with several interleukins (IL-1 $\beta$, IL-6, IL-8), S100B (a marker of increased blood brain barrier permeability and brain damage), protein $C$, and adiponectin associated with its development [28-30]. Inflammation is suspected to cause disruptions in the blood brain barrier and infiltration of leukocytes and cytokines, leading to neuronal apoptosis and synaptic dysfunction [31].

\section{Hormonal Dysregulation}

Circadian dysregulation leading to alterations in normal sleep architecture and disturbances in the hypothalamic-pituitary-adrenal axis leading to abnormally elevated levels of cortisol may also play a role [32]. Abnormally low levels of serum melatonin have been observed in ICU patients with delirium [33], and different delirium subtypes have been associated with either increased or decreased urinary melatonin metabolites [34]. Studies have shown that both pre- and postoperative elevated levels of cortisol correlate with delirium $[35,36]$, and failure to suppress secretion after dexamethasone administration has been correlated with risk of delirium in patients with stroke and dementia $[37,38]$. Elevated levels of glucocorticoids are postulated to leave neurons vulnerable to additional stressors [39].

\section{Other Mechanisms}

Associated factors include decreased oxidative metabolism secondary to atherosclerosis and ischemia [40], although studies examining the relation of white matter hyperintensities to delirium have produced conflicting results $[41,42]$. Finally, changes in the microarchitecture of the brain secondary to aging, with gradual accumulation of damage to neurons and astrocytes have also been postulated $[43,44]$.

\section{Causes of Delirium}

Causes of delirium may be grouped into either predisposing factors (vulnerabilities) or precipitating factors (triggers) [45]. Some of the most common predisposing factors include older age, dementia, multiple medical illnesses, history of alcohol use, sensory impairments, depression, and poor functional status [46], while common precipitants in hospitalized patients include medications (particularly psychotropic medications), infection, metabolic abnormalities, surgery, urinary catheterization, and pain $[47,48]$. Predisposing factors are of clinical importance in identifying patients at high risk of delirium in hospital settings [46], since a greater burden of predisposing factors renders patients more at risk for developing delirium in the presence of fewer precipitating factors. Models to predict delirium, such as the PRE-DELIRIC (Prediction of Delirium in ICU Patients) have been developed with promising results [49], but it is not yet clear that these models offer a reliable predictive value in older patient populations, who may benefit most from screening.

Delirium should be treated as a medical emergency until proven otherwise, with many potentially fatal etiologies-including seizures, intracranial bleeding, hypoxemia, hypoglycemia, hypertensive crisis, infection, metabolic or electrolyte abnormalities, and substance intoxication or withdrawal-ruled out early in its presentation. "Hospital delirium" or "ICU delirium" does not exist, and delirium should never be attributed to the mere environment of the hospital setting. 


\section{Diagnosis of Delirium}

Delirious patients may present as agitated or stuporous, with paranoia, frank delusions, visual hallucinations, disorganized thinking, and disorientation; subtypes of delirium include hyperactive, hypoactive, or mixed [50]. A key component of delirium is its fluctuating nature, often described as waxing and waning: patients may appear alternately lucid and disoriented. The DSM- 5 and ICD-10 diagnostic criteria differ slightly but both reflect this general definition $[1,2]$.

Prompt identification of delirium is critical, as delirium may be the sole manifestation of systemic illness, and correct identification will lead to investigation of the underlying pathology. Of the numerous formal measures available, the Confusion Assessment Method (CAM) is the most widely used [51] and has been adapted for specific environments requiring more rapid assessments [52], such as intensive care settings [8]. Additional diagnostic measures, such as the 4AT test, have also demonstrated similar sensitivities and specificities [53], and the latter may be more reliable in diagnosing the hypoactive subtype [54]. More recently, so-called "ultrabrief" measures (such as asking the patient to recite the months of the year backward) have also demonstrated high sensitivity [55], although the generalizability of these briefer screens needs further study [56].

Importantly, most validation studies of delirium assessment tools were performed by researchers who were specifically trained in the measure being studied, which may limit generalizability [54]. When evaluating for possible delirium in inpatient settings, it is useful to include both a structured examination of the patient that includes screening for inattention, disorientation, changes in arousal, and bizarre thought content, along with observation of any abnormalities in grooming, dress, affect, speech, or motoric changes. Since an integral element of delirium is its fluctuating nature, it is essential to gather information regarding the patient's mental state over time, closely review prior documentation for clues of changes in mental state, and review objective information (e.g., labs, culture data, imaging) for evidence of common precipitating causes of delirium. In cases where the patient's baseline may be unclear, collateral information from a family member can provide additional useful information.

\section{Prevention of Delirium}

Non-pharmacologic guidelines for the prevention of delirium in hospitalized patients have been developed and implemented with successful reduction in incidence and associated functional decline [57]; these guidelines have also been adapted for use in the perioperative setting [58], and a recent meta-analysis of 14 studies found significant reduc- tions in incidence of both delirium and falls [59]. These multi-component strategies target physical, cognitive, functional, and sensory parameters and include interventions such as frequent reorientation, early mobilization, sleep cycle regulation, and correction of hearing and visual deficits.

Pharmacologic interventions have also been investigated for the prevention of delirium; however, these interventions have yielded mixed results. Despite promising studies finding that antipsychotics were effective in reducing either the incidence [60] or the severity of post-operative delirium following elective major surgery [61], trials in critical care populations have not found benefit in reducing delirium incidence [62] or survival [63]. Larger meta-analyses of hospitalized patients have not found evidence supporting the use of antipsychotics as a preventative strategy $[64,65]$. Recent meta-analyses regarding melatonin or melatonin receptor agonist prophylaxis have reached conflicting conclusions; whereas a Cochrane review did not find evidence that melatonin treatment prevented delirium [65], a meta-analysis published the same year found that patients admitted for medical, but not surgical conditions benefited from melatonin or ramelteon [66]. Dexmedetomidine has generated interest following promising studies across various ICU patient populations, the results of which appear to be supported by a meta-analysis of 14 randomized trials including over 3,000 medical and surgical ICU patients, which found that dexmedetomidine administration resulted in a significantly decreased incidence of delirium [67].

\section{Treatment of Delirium}

The main strategy for managing delirium is to identify and reverse its underlying causes; this is especially important when the cause has the potential to be serious or life-threatening. However, despite adequate treatment, it may take substantial time before delirium resolves, especially for patients who have multiple underlying risk factors for delirium. When delirium is accompanied by significant agitation that interferes with care (e.g., pulling at catheters or central lines), pharmacologic interventions frequently are employed to improve patient safety and comfort (Table 2).

\section{Antipsychotics}

Antipsychotic medications have long been considered mainstays of treatment for agitation in delirium. Of these agents, haloperidol remains the oldest and best-studied, although most studies are small, unblinded, and limited to delirium in specific settings or disease states. A Cochrane review and meta-analysis examining antipsychotics for delirium included three studies where haloperidol was compared to olanzapine, risperidone, or placebo, respectively, and found no difference in delirium scores between groups treated with haloperidol or atypical antipsychotics; however, haloperidol was more effective than placebo [68]. Neither

Table 2. Pharmacologic Management of Agitation in Delirious Patients

\begin{tabular}{|l|l|l|l|}
\hline Medication Class & \multicolumn{1}{|c|}{ Benefits } & \multicolumn{1}{|c|}{ Adverse Effects } & \multicolumn{1}{c|}{ Special Considerations } \\
\hline Antipsychotics & $\begin{array}{l}\text { Several available as intramuscular } \\
\text { and/or intravenous preparations } \\
\text { for more rapid onset/effect. Useful } \\
\text { for acute agitation. }\end{array}$ & $\begin{array}{l}\text { Extrapyramidal side effects (tremor, } \\
\text { dystonia, tardive dyskinesia, } \\
\text { akathisia); prolongation of QTc } \\
\text { interval, orthostasis, anticholinergic } \\
\text { effects (adverse effects vary across } \\
\text { different agents). }\end{array}$ & $\begin{array}{l}\text { Elderly patients at higher risk of extrapyramidal } \\
\text { side effects; FDA black box warning re: } \\
\text { increased risk of mortality in patients with } \\
\text { dementia. }\end{array}$ \\
\hline $\begin{array}{l}\text { Mood Stabilizers } \\
\text { (Valproic Acid) }\end{array}$ & $\begin{array}{l}\text { Some evidence to support use } \\
\text { in impulsivity in non-delirious } \\
\text { patients; little evidence in delirium. }\end{array}$ & $\begin{array}{l}\text { Elevated liver function tests/ } \\
\text { hepatotoxicity, pancreatitis, } \\
\text { thrombocytopenia, weight gain (in } \\
\text { chronic use), tremor, ataxia. }\end{array}$ & $\begin{array}{l}\text { May be used as a second or third line agent } \\
\text { for management of agitation where use of } \\
\text { antipsychotics is limited by side effects or has } \\
\text { been ineffective. May be useful if concern for } \\
\text { comorbid epilepsy. }\end{array}$ \\
\hline Trazodone & $\begin{array}{l}\text { Achieves mild to moderate } \\
\text { sedation with fewer adverse } \\
\text { effects than antipsychotics. }\end{array}$ & $\begin{array}{l}\text { Hypotension; priapism (rare). } \\
\text { Provides rapid onset and easily be safer than neuroleptics (at low doses) in } \\
\text { reversible sedation (at lower } \\
\text { elderly patients. }\end{array}$ \\
\hline Dexmedet & Bradycardia, hypotension. & Restricted to intensive care unit settings. \\
\hline
\end{tabular}

QTc interval, Corrected QT interval. 
individual studies nor pooled data have found significant differences in efficacy between specific antipsychotic agents, or between-group differences comparing typical agents to the newer atypical antipsychotics such as olanzapine [69], risperidone [70], or aripiprazole [71,72].

More recent literature has called into question the efficacy of antipsychotics in reducing the severity of symptoms or duration of delirium due to severe methodological limitations of studies, including lack of adequate control groups, small sample size, non-randomization, or absence of placebo [73]. Furthermore, a recent Cochrane review specifically examining non-ICU patients did not find evidence that antipsychotics (typical or atypical) reduced severity or resolved symptoms of delirium [74]. They also noted the lack of observation across all studies of longer term delirium outcomes such as hospital length of stay, long-term health-related quality of life, or cognitive outcomes [74]. Additionally, antipsychotics are associated with a risk of several adverse effects, such as prolongation of the corrected QT interval and risk of torsades de pointes [75,76]. Patients at the greatest risk for delirium also appear to be at highest risk of several antipsychotic-related adverse effects, with the risk of tardive dyskinesia being three to five times greater in patients over the age of 55 [77]. Of greater concern, in 2003 the Food and Drug Administration warned prescribers of an increased risk of cerebrovascular events in elderly patients being given atypical antipsychotics [78], and in 2005, issued a black-box warning about increased all-cause mortality in elderly patients with dementia taking atypical antipsychotics [79]. Though these findings have proven somewhat controversial, caution should be exercised when using these agents in delirium, particularly in elderly patients with dementia.

\section{Anticonvulsants, Anxiolytics, and Antidepressants}

Due to its limited effect on the corrected QT interval, action on multiple neurotransmitter systems, and use in agitation secondary to other disorders, such as traumatic brain injury [80], valproic acid has been proposed as an alternative to antipsychotics in the management of clinical symptoms of hyperactive and mixed delirium, particularly in cases where conventional therapy is inadequate or limited [81]. However, studies supporting its efficacy are limited to small case series and one retrospective study, which found improvement in delirium symptoms following treatment [82]. To the authors' knowledge, other anticonvulsants, such as carbamazepine and gabapentin, have not been studied for treating delirium. There is not currently evidence to support the use of benzodiazepines in the treatment of delirium not associated with alcohol or GABA agonist withdrawal syndromes [83], but they may sometimes be used as an adjunct with haloperidol, both for reduction in severe agitation as well in prevention of extrapyramidal symptoms [84]. Of the antidepressants, trazodone has been used due to its sedative properties, but with little evidence supporting its use [85].

\section{Alpha-2 Adrenergic Agonists}

Alpha-2 adrenergic agonists are centrally acting compounds that reduce noradrenergic activity and induce sedation; they are particularly attractive for managing agitation in hospital settings due to their absence of effect on respiratory drive [86]. Initially used as a centrally-acting antihypertensive agent, clonidine is sometimes used for sedation in intensive care settings, despite a lack of clinical trials supporting its use, which is frequently limited by clinically significant hypotension [87]. Dexmedetomidine, which is 7-8 times more selective than clonidine for alpha-2 versus alpha-1 receptors, has fewer adverse effects than clonidine on heart rate and blood pressure [88]; these remain common, however, and use of dexmedetomidine is currently limited to intensive care settings. As the risk of bradycardia and hypotension may be at least partially related to whether or not a loading dose is administered, specific dosing protocols may be used to minimize the risk of hypotension [89]. Dexmedetomidine has been increasingly investigated as a treatment for delirium in the intensive-care setting, with a randomized but open-label trial finding superiority over haloperidol in treating delirious, intubated patients [90], and a recent, randomized and placebo-controlled trial finding an increase in ventilator-free hours in intubated patients with agitated delirium limiting extubation [91].
In practice, based on the available evidence as well as clinical experience, antipsychotics will likely remain the standard of care for the foreseeable future for the management of acute agitation secondary to delirium in cases where behavioral interventions have failed. For agitation secondary to delirium in the intensive care unit, particularly for ventilated patients, dexmedetomidine may be a reasonable alternative. In cases that are refractory to these agents or when treatment is limited by intolerable or unsafe adverse effects, mood stabilizers may be considered as an alternative.

\section{Conclusions}

Delirium is a commonly encountered clinical entity that is associated with poor cognitive and physical health outcomes. Although its pathophysiology remains poorly understood, both structural and molecular factors may contribute to its clinical symptoms. Given its impact on health, programs to identify those at risk for delirium, prevent the incidence of delirium, and identify it early are critically important. If delirium is diagnosed, treatment remains identifying and addressing its underlying cause. While some evidence indicates that pharmacologic agents may be beneficial in specific patient populations, evidence for use is limited, and, in the absence of acute agitation, the widespread use of medications across all delirium patient populations should be discouraged. Future research should focus on better understanding the pathophysiology, identification, and treatment of delirium, as minimizing its incidence and duration has the potential to improve both mental and physical health in the short- and long-term.

\section{Article Information}

* Correspondence: Christopher M. Celano, MD

Massachusetts General Hospital, 55 Fruit Street, Boston, MA, 02114, USA. E-mail: ccelano@partners.org

Received: Sep. 18, 2018; Accepted: Sep. 28, 2018; Published: Oct. 12, 2018

\section{DOI: 10.24983/scitemed.cmt.2018.00085}

Copyright (c) 2018 The Author (s). This is an open-access article distributed under the terms of the Creative Commons Attribution 4.0 International License (CC-BY).

\section{Funding: None}

\section{Conflict of Interest: None}

\section{Keywords}

Delirium; diagnosis; pathophysiology; prevention; treatment.

\section{References}

1. World Health Organization. ICD-10: international statistical classification of diseases and related health problems: tenth revision. 2nd ed. Geneva: World Health Organization; 2004. Available at: http://www. who.int/iris/handle/10665/42980. Accessed August 10, 2018.

2. American Psychiatric Association. Diagnostic and statistical manual of mental disorders. 5th ed. Washington, DC: Author; 2013.

3. Inouye SK, Rushing JT, Foreman MD, Palmer RM, Pompei P. Does delirium contribute to poor hospital outcomes? A three-site epidemiologic study. J Gen Intern Med 1998;13(4):234-242.

4. Trzepacz PT, Breitbart W, Franklin J, Levenson J, Richard Martini D, Wang P. Treatment of patients with delirium. In: Practice Guideline for the treatment of patients with delirium. Trzepacz PT, cheir. American Psychiatric Association, APA Press; 2010.

5. Davis DH, Kreisel SH, Muniz Terrera G, et al. The epidemiology of delirium: challenges and opportunities for population studies. Am J Geriatr Psychiatry 2013;21(12):1173-1189.

6. Addesi D, Maio R, Smirne N, et al. Prevalence of delirium in a popu- 
lation of elderly outpatients with dementia: a retrospective study. J Alzheimers Dis 2018;61(1):251-257.

7. Kuczmarska A, Ngo LH, Guess J, et al. Detection of delirium in hospitalized older general medicine patients: a comparison of the 3D-CAM and CAM-ICU. J Gen Intern Med 2016;31(3):297-303.

8. Ely EW, Inouye SK, Bernard GR, et al. Delirium in mechanically ventilated patients: validity and reliability of the confusion assessment method for the intensive care unit (CAM-ICU). JAMA 2001;286(21):2703-2710.

9. Watt J, Tricco AC, Talbot-Hamon C, et al. Identifying older adults at risk of delirium following elective surgery: a systematic review and meta-analysis. J Gen Intern Med 2018;33(4):500-509.

10. Vasilevskis EE, Han JH, Hughes CG, Ely EW. Epidemiology and risk factors for delirium across hospital settings. Best Pract Res Clin Anaesthesiol 2012;26(3):277-287.

11. Ouimet S, Kavanagh BP, Gottfried SB, Skrobik Y. Incidence, risk factors and consequences of ICU delirium. Intensive Care Med 2007;33(1):66-73.

12. Laurila JV, Pitkala KH, Strandberg TE, Tilvis RS. Impact of different diagnostic criteria on prognosis of delirium: a prospective study. Dement Geriatr Cogn Disord 2004;18(3-4):240-244.

13. Shehabi Y, Riker RR, Bokesch PM, et al. Delirium duration and mortality in lightly sedated, mechanically ventilated intensive care patients. Crit Care Med 2010;38(12):2311-2318.

14. McCusker J, Cole MG, Dendukuri N, Belzile E. Does delirium increase hospital stay? J Am Geriatr Soc 2003;51(11):1539-1546.

15. Davis DH, Muniz Terrera G, Keage $H$, et al. Delirium is a strong risk factor for dementia in the oldest-old: a population-based cohort study. Brain 2012;135(Pt 9):2809-2816.

16. Witlox J, Eurelings LS, de Jonghe JF, Kalisvaart KJ, Eikelenboom P, van Gool WA. Delirium in elderly patients and the risk of postdischarge mortality, institutionalization, and dementia: a meta-analysis. JAMA 2010;304(4):443-451.

17. Leslie DL, Inouye SK. The importance of delirium: economic and societal costs. J Am Geriatr Soc 2011;59 Suppl 2:241-243.

18. National Institute for Health and Clinical Excellence (NICE). Delirium: diagnosis, prevention and management, Clinical guidelines, CG103. 2010. Available at: https://www.nice.org.uk/guidance/cg103. Accessed August 10, 2018.

19. Filley CM. The neuroanatomy of attention. Semin Speech Lang 2002;23(2):89-98.

20. Fong TG, Bogardus ST Jr, Daftary A, et al. Cerebral perfusion changes in older delirious patients using 99mTc HMPAO SPECT. J Gerontol A Biol Sci Med Sci 2006;61(12):1294-1299.

21. Cavallari M, Dai W, Guttmann CR, et al. Neural substrates of vulnerability to postsurgical delirium as revealed by presurgical diffusion MRI. Brain 2016;139(Pt 4):1282-1294.

22. Choi SH, Lee $H$, Chung TS, et al. Neural network functional connectivity during and after an episode of delirium. Am J Psychiatry 2012;169(5):498-507.

23. Trzepacz PT. Is there a final common neural pathway in delirium? Focus on acetylcholine and dopamine. Semin Clin Neuropsychiatry 2000;5(2):132-148.

24. Han L, McCusker J, Cole M, Abrahamowicz M, Primeau F, Elie M. Use of medications with anticholinergic effect predicts clinical severity of delirium symptoms in older medical inpatients. Arch Intern Med 2001;161(8):1099-1105.

25. Yilmaz S, Aksoy E, Diken Al, Yalcinkaya A, Erol ME, Cagli K. Dopamine administration is a risk factor for delirium in patients undergoing coronary artery bypass surgery. Heart Lung Circ 2016;25(5):493-498.

26. Trzepacz PT. Delirium. Advances in diagnosis, pathophysiology, and treatment. Psychiatr Clin North Am 1996;19(3):429-448.

27. van der Mast RC, van den Broek WW, Fekkes D, Pepplinkhuizen L, Habbema JD. Is delirium after cardiac surgery related to plasma amino acids and physical condition? J Neuropsychiatry Clin Neurosci 2000;12(1):57-63.
28. Ritter C, Tomasi CD, Dal-Pizzol F, et al. Inflammation biomarkers and delirium in critically ill patients. Crit Care 2014;18(3):R106.

29. van Munster $\mathrm{BC}$, Bisschop $\mathrm{PH}$, Zwinderman $\mathrm{AH}$, et al. Cortisol, interleukins and $\mathrm{S} 100 \mathrm{~B}$ in delirium in the elderly. Brain Cogn 2010;74(1):18-23.

30. Dillon ST, Vasunilashorn SM, Ngo L, et al. Higher C-Reactive protein levels predict postoperative delirium in older patients undergoing major elective surgery: a longitudinal nested case-control study. Biol Psychiatry 2017;81(2):145-153

31. Cerejeira J, Firmino H, Vaz-Serra A, Mukaetova-Ladinska EB. The neuroinflammatory hypothesis of delirium. Acta Neuropatho 2010;119(6):737-754.

32. Maclullich AM, Ferguson KJ, Miller T, de Rooij SE, Cunningham C. Unravelling the pathophysiology of delirium: a focus on the role of aberrant stress responses. J Psychosom Res 2008;65(3):229-238.

33. Miyazaki $\mathrm{T}$, Kuwano $\mathrm{H}$, Kato $\mathrm{H}$, et al. Correlation between serum melatonin circadian rhythm and intensive care unit psychosis after thoracic esophagectomy. Surgery 2003;133(6):662-668.

34. Balan S, Leibovitz A, Zila SO, et al. The relation between the clinical subtypes of delirium and the urinary level of 6-SMT.J Neuropsychiatry Clin Neurosci 2003;15(3):363-366.

35. Kudoh A, Takase $\mathrm{H}$, Katagai $\mathrm{H}$, Takazawa $\mathrm{T}$. Postoperative interleukin- 6 and cortisol concentrations in elderly patients with postoperative confusion. Neuroimmunomodulation 2005;12(1):60-66.

36. Kazmierski J, Banys A, Latek J, Bourke J, Jaszewski R. Cortisol levels and neuropsychiatric diagnosis as markers of postoperative delirium: a prospective cohort study. Crit Care 2013;17(2):R38.

37. Marklund N, Peltonen M, Nilsson TK, Olsson T. Low and high circulating cortisol levels predict mortality and cognitive dysfunction early after stroke. J Intern Med 2004;256(1):15-21.

38. Robertsson B, Blennow K, Bråne G, et al. Hyperactivity in the hypothalamic-pituitary-adrenal axis in demented patients with delirium. Int Clin Psychopharmacol 2001;16(1):39-47.

39. MacLullich AM, Ferguson KJ, Miller T, de Rooij SE, Cunningham C. Unravelling the pathophysiology of delirium: a focus on the role of aberrant stress responses. J Psychosom Res 2008;65(3):229-238.

40. Harukuni I, Bhardwaj A. Mechanisms of brain injury after global cerebral ischemia. Neurologic Clinics 2006;24(1):1-21.

41. Cavallari M, Hshieh TT, Guttmann CR, et al. Brain atrophy and white-matter hyperintensities are not significantly associated with incidence and severity of postoperative delirium in older persons without dementia. Neurobiol Aging 2015;36(6):2122-2129.

42. Hatano $Y$, Narumoto J, Shibata K, et al. White-matter hyperintensities predict delirium after cardiac surgery. Am J Geriatr Psychiatry 2013;21(10):938-945.

43. Troncale JA. The aging process: physiologic changes and pharmacologic implications. Postgrad Med 1996;99(5):111-114,120-122.

44. Pinho C, Cruz S, Santos A, Abelha FJ. Postoperative delirium: age and low functional reserve as independent risk factors. J Clin Anesth 2016:33:507-513.

45. Inouye SK. Predisposing and precipitating factors for delirium in hospitalized older patients. Dement Geriatr Cogn Disord 1999;10(5):393400.

46. Ahmed S, Leurent B, Sampson EL. Risk factors for incident delirium among older people in acute hospital medical units: a systematic review and meta-analysis. Age Ageing 2014;43(3):326-333.

47. Inouye SK, Westendorp RG, Saczynski JS. Delirium in elderly people. Lancet 2014;383(9920):911-922.

48. Lynch EP, Lazor MA, Gellis JE, Orav J, Goldman L, Marcantonio ER. The impact of postoperative pain on the development of postoperative delirium. Anesth Analg 1998;86(4): 781-785.

49. van den Boogaard M, Pickkers $P$, Slooter AJ, et al. Development and validation of PRE-DELIRIC (PREdiction of DELIRium in ICU patients) delirium prediction model for intensive care patients: observational multicentre study. BMJ 2012;344:e420. 
50. Hosker C, Ward D. Hypoactive delirium. BMJ 2017;357:j2047.

51. Wei LA, Fearing MA, Sternberg EJ, Inouye SK. The Confusion Assessment Method: a systematic review of current usage. J Am Geriatr Soc 2008;56(5):823-830.

52. Marcantonio ER, Ngo LH, O'Connor M, et al. 3D-CAM: derivation and validation of a 3-minute diagnostic interview for CAM-defined delirium: a cross-sectional diagnostic test study. Ann Intern Med 2014;161(8):554-561.

53. Bellelli G, Morandi A, Davis DH, et al. Validation of the 4AT, a new instrument for rapid delirium screening: a study in 234 hospitalised older people. Age Ageing 2014;43(4):496-502.

54. De J, Wand AP. Delirium screening: a systematic review of delirium screening tools in hospitalized patients. Gerontologist 2015;55(6):1079-1099.

55. Fick DM, Inouye SK, Guess J, et al. Preliminary development of an ultrabrief two-item bedside test for delirium. J Hosp Med 2015;10(10):645-650.

56. Han JH, Vasilevskis EE. Ultrabrief delirium assessments--are they ready for primetime? J Hosp Med 2015;10(10):694-695.

57. Inouye SK, Bogardus ST Jr, Baker DI, Leo-Summers L, Cooney LM Jr. The Hospital Elder Life Program: a model of care to prevent cognitive and functional decline in older hospitalized patients. Hospital Elder Life Program. J Am Geriatr Soc 2000;48(12):1697-1706.

58. Chen CC, Lin MT, Tien YW, Yen CJ, Huang GH, Inouye SK. Modified hospital elder life program: effects on abdominal surgery patients. J Am Coll Surg 2011;213(2):245-252.

59. Hshieh TT, Yue J, Oh E, et al. Effectiveness of multicomponent nonpharmacological delirium interventions: a meta-analysis. JAMA Intern Med 2015;175(4):512-520.

60. Larsen KA, Kelly SE, Stern TA, et al. Administration of olanzapine to prevent postoperative delirium in elderly joint-replacement patients: a randomized, controlled trial. Psychosomatics 2010;51(5):409-418.

61. Kalisvaart KJ, de Jonghe JF, Bogaards MJ, et al. Haloperidol prophylaxis for elderly hip-surgery patients at risk for delirium: a randomized placebo-controlled study. J Am Geriatr Soc 2005;53(10):1658-1666.

62. Page VJ, Ely EW, Gates S, et al. Effect of intravenous haloperidol on the duration of delirium and coma in critically ill patients (HopeICU): a randomised, double-blind, placebo-controlled trial. Lancet Respir Med 2013;1(7):515-523.

63. van den Boogaard $M$, Slooter AJC, Brüggemann RJM, et al. Effect of haloperidol on survival among critically ill adults with a high risk of delirium: The REDUCE randomized clinical trial. JAMA 2018;319(7):680-690.

64. Neufeld KJ, Yue J, Robinson TN, Inouye SK, Needham DM. Antipsychotic medication for prevention and treatment of delirium in hospitalized adults: a systematic review and meta-analysis. J Am Geriatr Soc 2016;64(4):705-714.

65. Siddiqi N, Harrison JK, Clegg A, et al. Interventions for preventing delirium in hospitalised non-ICU patients. Cochrane Database Syst Rev 2016;3:CD005563.

66. Chen S, Shi L, Liang F, Xu L, Desislava D, Wu Q, et al. Exogenous melatonin for delirium prevention: a meta-analysis of randomized controlled trials. Mol Neurobiol 2016;53(6):4046-4053.

67. Pasin, L., et al., Dexmedetomidine reduces the risk of delirium, agitation and confusion in critically III patients: a meta-analysis of randomized controlled trials. J Cardiothorac Vasc Anesth 2014;28(6):1459-1466.

68. Lonergan E, Britton AM, Luxenberg J, Wyller T. Antipsychotics for delirium. Cochrane Database Syst Rev 2007;18(2):CD005594.

69. Skrobik YK, Bergeron N, Dumont M, Gottfried SB. Olanzapine vs haloperidol: treating delirium in a critical care setting. Intensive Care Med 2004;30(3):444-449.

70. Han CS, YK Kim. A double-blind trial of risperidone and haloperidol for the treatment of delirium. Psychosomatics 2004;45(4):297-301.

71. Boettger S, Friedlander M, Breitbart W, Passik S. Aripiprazole and haloperidol in the treatment of delirium. Aust N Z J Psychiatry 2011;45(6):477-482.

72. Campbell N, Boustani MA, Ayub A, et al. Pharmacological management of delirium in hospitalized adults-a systematic evidence review. J Gen Intern Med 2009;24(7):848-853.

73. Flaherty JH, Gonzales JP, Dong B. Antipsychotics in the treatment of delirium in older hospitalized adults: a systematic review. J Am Geriatr Soc 2011;59:Suppl 2:S269-S276.

74. Burry L, Mehta S, Perreault MM, et al. Antipsychotics for treatment of delirium in hospitalised non-ICU patients. Cochrane Database Syst Rev 2018;6:CD005594.

75. Leucht S, Cipriani A, Spineli L, et al. Comparative efficacy and tolerability of 15 antipsychotic drugs in schizophrenia: a multiple-treatments meta-analysis. Lancet 2013;382(9896):951-962.

76. Haldol ${ }^{\circledR}$ (haloperidol injection for immediate release) [package insert]. Beerse, Belgium. Janssen Pharmaceutica N.V.; 2005. Available at: https://www.accessdata.fda.gov/drugsatfda_docs/label/2008/015923s082,018701s057lbl.pdf Accessed August 10, 2018.

77. Woerner MG, Alvir JM, Saltz BL, Lieberman JA, Kane JM. Prospective study of tardive dyskinesia in the elderly: rates and risk factors. Am J Psychiatry 1998;155(11):1521-1528.

78. Risperdal ${ }^{\circledR}$ (risperidone, full prescribing information). Titusville, FL: Janssen, Division of Ortho-McNeil-Janssen Pharmaceuticals Inc; 2009. Available at: https://www.accessdata.fda.gov/drugsatfda_docs/label/2010/020588s046lbl.pdf. Accessed August 10, 2018.

79. US Food and Drug Administration. Public health advisory: deaths with antipsychotics in elderly patients with behavioral disturbances. US Department of Health and Human Services. Available at: http://psychrights.org/drugs/FDAantipsychotics4elderlywarning.htm. Accessed August 10, 2018.

80. Chatham Showalter PE, Kimmel DN. Agitated symptom response to divalproex following acute brain injury.J Neuropsychiatry Clin Neurosci 2000;12(3):395-397.

81. Sher Y, Miller Cramer AC, Ament A, Lolak S, Maldonado JR. Valproic acid for treatment of hyperactive or mixed delirium: rationale and literature review. Psychosomatics 2015;56(6): 615-625.

82. Gagnon DJ, Fontaine GV, Smith KE, et al. Valproate for agitation in critically ill patients: a retrospective study. J Crit Care 2017;37:119125.

83. Lonergan E, Luxenberg J, Areosa Sastre A, Wyller TB. Benzodiazepines for delirium. Cochrane Database Syst Rev 2009;(1):CD006379.

84. Menza MA, Murray GB, Holmes VF, Rafuls WA. Controlled study of extrapyramidal reactions in the management of delirious, medically ill patients: intravenous haloperidol versus intravenous haloperidol plus benzodiazepines. Heart Lung 1988;17(3):238-241.

85. Huybrechts KF, Gerhard T, Crystal S, et al. Differential risk of death in older residents in nursing homes prescribed specific antipsychotic drugs: population based cohort study. BMJ 2012;344:e977.

86. Keating GM. Dexmedetomidine: a review of its use for sedation in the intensive care setting. Drugs, 2015;75(10):1119-1130.

87. Wang JG, Belley-Coté E, Burry L, et al. Clonidine for sedation in the critically ill: a systematic review and meta-analysis. Crit Care 2017;21(1):75.

88. Carollo DS, Nossaman BD, Ramadhyani U. Dexmedetomidine: a review of clinical applications. Curr Opin Anaesthesiol 2008;21(4):457461.

89. Gerlach AT, Dasta JF, Steinberg S, Martin LC, Cook CH. A new dosing protocol reduces dexmedetomidine-associated hypotension in critically ill surgical patients. J Crit Care 2009;24(4):568-574.

90. Reade MC, O'Sullivan K, Bates S, Goldsmith D, Ainslie WR, Bellomo $R$. Dexmedetomidine vs. haloperidol in delirious, agitated, intubated patients: a randomised open-label trial. Crit Care 2009;13(3):R75.

91. Reade MC, Eastwood GM, Bellomo R, et al. Effect of dexmedetomidine added to standard care on ventilator-free time in patients with agitated delirium: a randomized clinical trial. JAMA 2016;315(14):1460-1468. 